\title{
Reducing Pollen Moisture Simplifies Long-term Storage of Pecan Pollen
}

\author{
I.E. Yates \\ Russell Research Center, Agricultural Research Service, U.S. Department of Agriculture, Athens, \\ GA 30613 \\ Darrell Sparks \\ Department of Horticulture, University of Georgia, Athens, GA 30602
}

Kris Connor and Leigh Towill

Agricultural Research Service, U.S. Department of Agriculture, Colorado State University, Fort Collins, CO 80523

\begin{abstract}
Additional index words. Carya illinoensis, plant breeding, catkins, dehydration, viability, temperature
Abstract. Pecan [Carya illinoensis (Wangenh.) C. Koch] pollen was stored under reduced moisture conditions to determine if pollen viability could be maintained for long periods at either 23,5 , or $-12 \mathrm{C}$. Pecan pollen was ovendried at $35 \mathrm{C}$ to a constant weight and stored in moisture-proof bags. Pollen maintained at $-12 \mathrm{C}$ for 2 years was as viable as freshly collected pollen. The duration of viability at SC was at least 2 months. Even at 23C, viability was detectable for 1 month, but at a greatly reduced level. Provided precautions are taken to reduce pollen moisture before and during storage, long-term storage of pecan pollen can be easily accomplished with commonly available supplies and equipment.
\end{abstract}

Two features of the pecan reproductive cycle make pollen storage necessary. One, flowering does not occur until trees are several years old and two, flowering is heterodichogamous. Inducing flowering in the greenhouse to obtain pollen for either grower or experimental purposes is not practical because pecan trees may be $3 \mathrm{~m}$ tall or even taller before becoming reproductively mature. Under field conditions, pecan pollen from a single cultivar is usually available for only $\approx 8$ to 10 days of the year (Sparks, 1986). As a result of the heterodichogamy in pecan, the periods of peak stigmatic receptivity and pollen release may not overlap (Sparks, 1987); thus, pollination and fertilization between appropriate cultivars may not occur. In such cases, a cultivar with early stigmatic receptivity cannot be fertilized with a cultivar having late pollen release unless the pollen has been stored from the previous growing season.

Methods for long-term storage of pecan pollen are needed by pecan researchers, breeders, and growers (Yates and Sparks, 1990). A ready supply of pollen is necessary for many experimental studies; e.g., pollen physiology, biochemistry, or pollen-stigma interactions. Breeders may need to hybridize two selections and the female flowers may be receptive on the maternal plant before the pollen is mature on the paternal plant. For growers, climatic conditions in some years may not be conducive for timely pollen maturation in the pollenizer cultivar so that fertilization of the producer cultivar will require supplemental pollination (Bennett et al., 1986).

Pecan pollen viability has been the subject of several investigations (Smith and Romberg, 1933; Wetzstein and Sparks, 1985; Woodroof, 1930; Yates et al., 1986). These reports indicated pecan pollen was short-lived; however, Yates and Sparks $(1989,1990)$ recently demonstrated that pollen stored for up to 3 years at either -80 or $-196 \mathrm{C}$ is viable as assessed by both

Received for publication 12 Sept. 1990. Trade names are used in this publication to provide specific information. Mention of a trade name does not constitute a guarantee or warranty of the product or an endorsement by the U.S. Dept. of Agriculture over other products not mentioned. The cost of publishing this paper was defrayed in part by the payment of page charges. Under postal regulations, this paper therefore must be hereby marked advertisement solely to indicate this fact. in vitro germination tests and fruit set analyses. Nevertheless, storage at these temperatures is feasible only in well-equipped laboratories and for relatively small quantities of pollen. Researchers and breeders at field stations and growers in isolated areas may not have ready access to a source of liquid nitrogen required for maintaining $-196 \mathrm{C}$ or a freezer with the capacity of $-80 \mathrm{C}$. Even if available, such accommodations may not be adequate to store large amounts of pollen required by a grower to enhance fruit set. Consequently, techniques using easily accessible facilities and equipment capable of storing large quantities would be useful. Our objectives were to estimate the pollen recovery that could be expected from mass catkin collections and to develop methodology to maintain viable, stored pollen with inexpensive, commonly available supplies and equipment.

\section{Materials and Methods}

Pollen source. Samples were taken from each of four trees of 'Stuart' and 'Desirable' pecan growing at the Univ. of Georgia Horticulture Farm, Watkinsville. Catkins were collected on a day between 12:00 PM and 3:00 PM when the anthers had initiated pollen release. Catkins collected from each tree were weighed and then spread in single layers on wrapping paper in a laboratory maintained at $27 \mathrm{C}$ and $50 \% \mathrm{RH}$. Following a 24$\mathrm{h}$ dehiscence period, debris was removed by filtering the pollen through a brass screen with mesh openings of $120 \mu^{2}$. After determining the weight of pollen collected from each tree, pollen was stored at $-80 \mathrm{C}$ until used for analyses of the kinetics of pecan pollen dehydration and drying.

Following the collection of pollen, catkins from the 'Stuart' trees were spread on wrapping paper without regard to source tree. The pollen released after another $24 \mathrm{~h}$ was then collected to form a composite pollen from all four trees. This pollen sample was used to determine the effects of drying on the viability of stored pollen.

Drying 'Stuart' pollen before storage. Our objectives in drying pollen were to 1) determine initial moisture content by thermogravimetric methods and 2) analyze the effects of drying time on the viability of stored pollen. The composite 'Stuart' pollen was divided into samples of $\approx 0.7 \mathrm{~g}$ each. Samples to be dried 
were dispensed onto dried glass plates in a layer of $<0.5 \mathrm{~mm}$. Plates with pollen were weighed on an analytical balance and placed in a mechanical convection oven at 35C. Four plates with pollen were removed after drying for each of the following periods: 1, 3, 6, 12, 24, and $48 \mathrm{~h}$. Samples removed from the oven were equilibrated to room temperature for $10 \mathrm{~min}$ in desiccation vessels containing $\mathrm{CaSO}_{4}$ and then weighed to estimate moisture loss during drying. After being weighed, the dried pollen was placed in food storage bags enclosed in moisture-proof bags [mil-b-121 E, Grade A, Type II, Class I, 6“ $\times$ 8“ (Edco Supply, Brooklyn, N.Y.)], a type that has been used to maintain constant moisture concentrations $\mathrm{m}$ forage (Wmdham et al., 1988). After sealing the moisture-proof bags with a hot iron, samples were stored at $-12 \mathrm{C}$ in a household freezer. Control samples that were not dried before storage were bagged in the same manner as the dried samples. Dried and nondried pollen samples were tested by in vitro germination assays after storage for 2 years to determine the effects of drying time on viability. In addition to long-term storage at $-12 \mathrm{C}$, pollen that was dried for $1 \mathrm{~h}$ and pollen that was not dried were analyzed for viability after storage in moisture-proof bags at higher temperatures (23 and $5 \mathrm{C})$ and for shorter storage periods $(4,16$, 30 , and 60 days ).

Kinetics of pollen dehydration and drying. Small quantities of fresh pollen $(0.7 \mathrm{~g})$ with low initial moisture content $(4 \%)$ were used in the previous experiments to determine the effects of drying on the viability of stored pollen. We also assessed possible differences in drying and rehydration requirements for larger quantities of pollen,. Pollen was dehydrated to equilibrium moisture conditions before drying by dispensing it in a $6.0-\mathrm{mm}$ layer on dried glass plates $(160 \times 180 \mathrm{~mm})$ maintained at $25 \mathrm{C}$ and $97.2 \%$ RH. A constant $97.2 \%$ RH was maintained with $\mathrm{CuSO}_{4}$ in desiccation vessels (Young, 1967). Pollen weight was determined after 6 and $12 \mathrm{~h}$ and every $12 \mathrm{~h}$ thereafter until an increase in weight was barely detectable over a 12 -h period. For drying, the dehydrated pollen was portioned out in $0.3,0.6$, 3.0 , and $6.0 \mathrm{~g}$ quantities at a thickness of $\approx 0.3,0.6,3.0$, and $6.0 \mathrm{~mm}$, respectively, in flint glass vessels (45 mm I.D. x 45 $\mathrm{mm}$ height). Vessels containing pollen were placed in a convection oven at $35 \mathrm{C}$ and weighed after $1,3,6,12$, and $24 \mathrm{~h}$ of drying. Likewise, the same quantities of pollen $(0.3,0.6,3.0$, and $6.0 \mathrm{~g}$ ) used in the pollen drying experiments were rehydrated. Pollen contained in flint glass vessels with the same dimensions as used for dehydration was placed at $97.2 \% \mathrm{RH}$ and $25 \mathrm{C}$. Weight determinations were made after $4,8,12$, and $24 \mathrm{~h}$ of dehydration.

Assessment of pecan pollen viability. Viability of pecan pollen was determined by in vitro germination using the methods of Yates and Sparks (1989). Pollen was dehydrated at 97.2\% $\mathrm{RH}$ and $25 \mathrm{C}$ for $4 \mathrm{~h}$. Pollen grains were then incubated overnight at $25 \mathrm{C}$ in $0.2 \mathrm{ml}$ germination medium containing $15 \%$ sucrose, $0.02 \%$ boric acid, and $0.05 \%$ calcium nitrate tetrahydrate. At least 200 pollen grains from each of four assay tubes were counted per pollen storage treatment. Pollen germination was determined microscopically by counting grains in ten $5-\mu 1$ drops placed on a microscope slide. Pollen grains were scored as germinated if the tube length equaled or exceeded grain diameter.

Statistical analyses. All experiments were replicated four times and data were analyzed by $t$ test and regression (Snedecor and Cochran, 1967). For Mitscherlich's plant growth model, the $r^{2}$ value was calculated as 1.0 minus the ratio of the residual sum of squares to the corrected total sum of squares (Ware et al., 1982).

\section{Results}

Pollen recovery per kilogram of catkins. Pollen obtained from mass collections of 'Desirable' and 'Stuart' catkins was $\approx 370$ to $4 \%$ of the fresh weight of catkins (Table 1 ). The amount of pollen recovered per given quantity of catkins was not statistically different between the cultivars. However, pollen recovery among 'Desirable' trees was more variable than among 'Stuart' trees with coefficients of variation being $11.9 \%$ and $6.5 \%$, respectively.

Viability of 'Stuart 'pollen dried before storage. Pollen dried to a constant weight (Fig. 1A) before storage in moisture-proof bags and held for 2 years in a household freezer at $-12 \mathrm{C}$ re-

Table 1. Pollen recovery from pecan catkins.

\begin{tabular}{lccc}
\hline \hline Tree_.no. & Catkin wt $(\mathrm{kg})$ & Pollen wt $(\mathrm{g})$ & Pollen recovery $(\%)^{2}$ \\
\hline & & 'Desirable' & \\
1 & 1.8 & 63.6 & 3.5 \\
2 & 1.5 & 63.3 & 4.2 \\
3 & 0.9 & 28.8 & 3.2 \\
4 & 1.5 & 57.0 & 3.9 \\
Mean & & & 3.7 \\
& & 'Stuart' & \\
1 & 1.0 & 30.0 & 3.0 \\
2 & 1.7 & 57.0 & 3.4 \\
3 & 1.3 & 30.0 & 3.0 \\
4 & 1.0 & 33.0 & 3.3 \\
Mean & & & 3.2 \\
\hline
\end{tabular}

${ }^{2}$ Analysis of the cultivar means: $t$ test, not statistically significant.

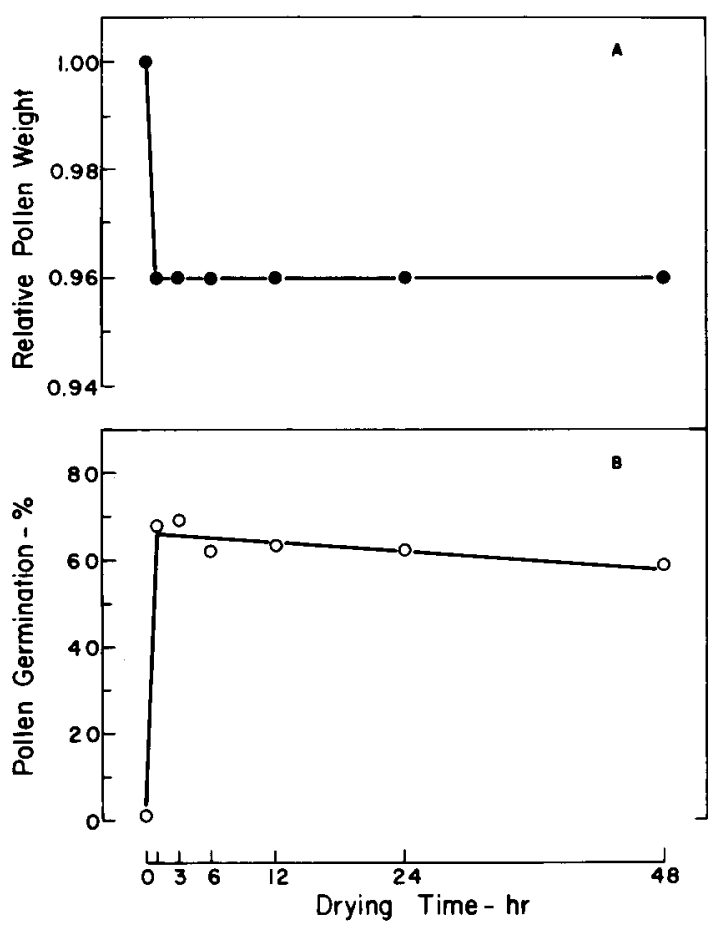

Fig. 1. Drying and viability of 'Stuart' pollen stored at $-12 \mathrm{C}$. (A) Relative pollen weight after drying for up to $48 \mathrm{~h}$. The weight of fresh pollen was expressed as 1.0 and other values relative to the fresh pollen. (B) Percentage in vitro germination of dried pollen after storage for 2 years. The relationships are described by the following equations. For Fig. 1A: $\mathrm{Y}=0.9607+0.00041 / \mathrm{x}, r^{2}=0.9798$, S.E.E. $=50.002$; For Fig. IB: $\mathrm{Y}=67.25-0.1846 \mathrm{X}-0.6622$ $1 / \mathrm{x}, R^{2}=0.9732$, S.E.E. $= \pm 0.4 \%$. Regression coefficients are significantly different from zero. $P \leq 0.01$. 
tained viability at the same level as freshly collected pollen $(65 \% \pm 5 \%)$ (Fig. 1B). The pollen used for these experiments lost $4 \%$ of its fresh weight within $1 \mathrm{~h}$ and further drying time did not increase moisture loss (Fig. 1A). Drying at 35C for 1 $\mathrm{h}$ preserved viability of pollen stored in the freezer at $-12 \mathrm{C}$. There was a slight but statistically significant decrease in viability with longer drying time (Fig. 1B). Nondried pollen, i.e., zero drying time (Fig. 1B), kept at $-12 \mathrm{C}$ for 2 years had nearly zero viability in spite of being stored in moisture-proof bags.

Pollen stored at room temperature (23C) in moisture-proof bags lost viability over 60 days in spite of being dried before storage (Fig. 2). However, dried pollen lost viability at a slower rate than nondried pollen. After storage for 30 days, viability of nondried pollen had decreased to only $2 \%$; whereas the viability of dried pollen was $\approx 30 \%$.

The viability of both dried and nondried pollen stored in a refrigerator at $5 \mathrm{C}$ remained within $10 \%$ of initial in vitro germination for 60 days (Fig. 2). In all cases, except nondried pollen stored at $23 \mathrm{C}$, there was a differential change in germination with time stored. Germination decreased following 4 days of storage (Fig. 2) followed either by no additional decrease in germination (pollen stored at $5 \mathrm{C}$ ) or a reduced rate of change (pollen dried and stored at 23C).

Kinetics of pollen dehydration and drying. The pollen used in the experiments to determine viability after storage in moisture-proof bags (Figs. 1B and 2) had been dried in small quantities for in vitro germination tests that required only minimal amounts of pollen. To determine whether larger quantities of

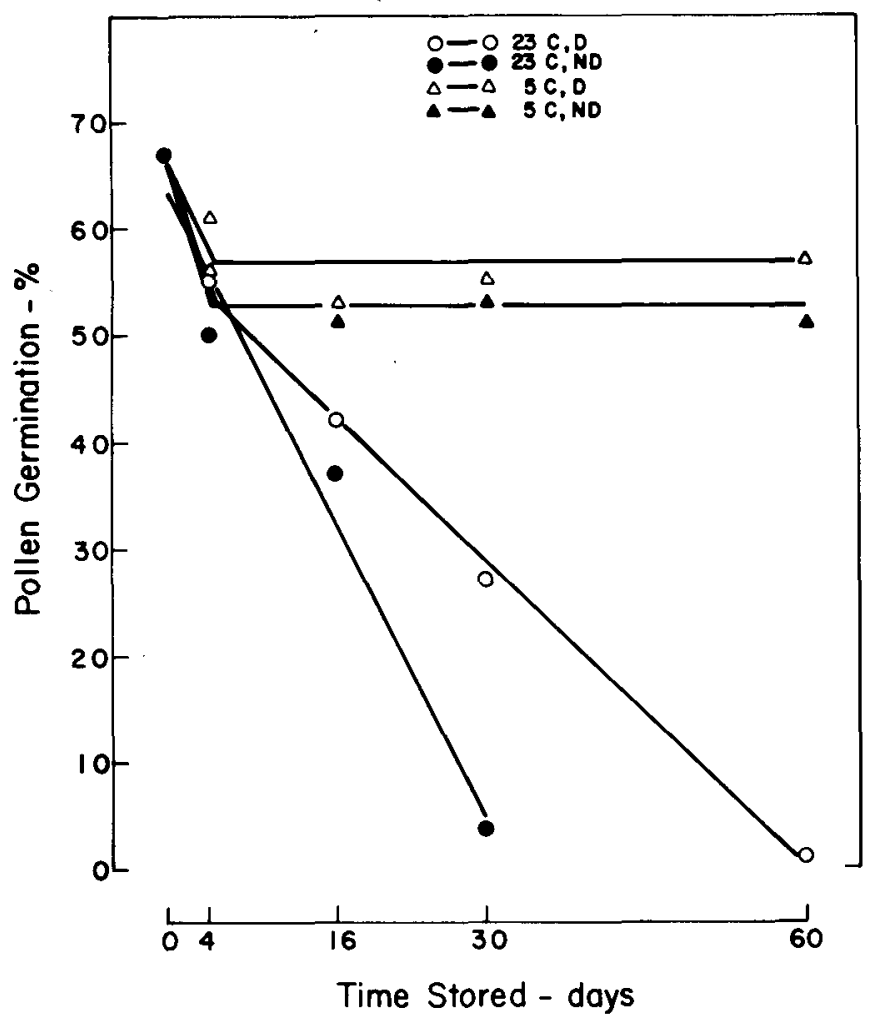

Fig. 2. Viability of pecan pollen stored at 23 and SC. Abbreviations: $\mathrm{D}=$ dried, $\mathrm{ND}=$ not dried. The relationships are described by the following equations. For 23C,D: $\mathrm{Y}=57.25-0.9521 \mathrm{X}+0.0927$ $1 / \mathrm{x}, R^{2}=0.9847$, S.E.E. $= \pm 3.1 \%$; for $23 \mathrm{C}$, ND: $\mathrm{Y}=63.89-$ $1.9742 \mathrm{X}, r^{2}=0.9581$, S.E.E. $= \pm 5.2 \%$; for $5 \mathrm{C}, \mathrm{D}: \mathrm{Y}=56.56$ $+0.09961 / \mathrm{x}, r^{2}=0.5262$, S.E.E. $= \pm 4.1 \%$; for $5 \mathrm{C}, \mathrm{ND}: \mathrm{Y}=$ $52.68+0.13861 \mathrm{x}, r^{2}=0.6953$, S.E.E. $= \pm 3.9 \%$. Regression coefficients are significantly different from zero. $P \leq 0.01$. pollen with a high moisture content would require longer drying times to stabilize weight loss, pollen was dehydrated to a constant moisture content and then dried in various quantities. The moisture gained by this pollen was $22.3 \%$ after $72 \mathrm{~h}$ of rehydration at $97.2 \% \mathrm{RH}$ and $25 \mathrm{C}$ (Fig. 3). On exposure to drying conditions at $35 \mathrm{C}$, this pollen lost $20.2 \%$ of its dehydrated weight within $1 \mathrm{~h}$ at $35 \mathrm{C}$ (Fig. 4). The rate of pecan pollen drying was independent of the pollen quantity. In contrast, the rate of pollen dehydration depended on pollen quantity. Even though pollen dispensed in $0.3,0.6,3.0$, and $6.0 \mathrm{~g}$ quantities all lost $\approx 20 \%$ of their weight after drying for $1 \mathrm{~h}$ (Fig. 4), weight gain under dehydration conditions was much slower and varied according to the amount of pollen being treated (Fig. 5). After $24 \mathrm{~h}$, only the smallest pollen quantity, $0.3 \mathrm{~g}$, had gained $18.1 \%$ of its weight (Fig. 5), which approached maximum dehydration content as demonstrated by longer dehydration times (Fig. 3).

\section{Discussion}

Woodroof (1924) reported a pollen recovery from 'Teche' catkins of $27.4 \%$ and from 'Nelson' anthers of $33.3 \%$ of the weight of the catkins, respectively, after anther dehiscence. In our study, pollen recovery was only $\approx 3 \%$ to $4 \%$. There are several differences involved in these two studies. Woodroof worked with only "fully ripe" catkins. In a mass collection, as described in the current study, not all catkins will be "fully ripe". As commonly observed, pecan staminate flowers do not mature at the same time either on different trees of the same cultivar, on the same tree, or on the same inflorescence. In addition, our data are based on the initial fresh weight of catkins before anther dehiscence and pollen weight after $24 \mathrm{~h}$ of anther dehiscence; whereas Woodroof (1924) weighed the catkins after anther dehiscence and after the catkins had dried to an unknown degree. Apparently, catkins analyzed by Woodroof were at least air-dried, as his results are in fair agreement with those of Davis and Sparks (1971) who reported that catkin oven-dried weight of 'Stuart' decreases $\approx 37 \%$ following dehiscence. Thus, on a catkin fresh weight basis, pollen yield is relatively low, but the amount of pollen recovered will depend on the degree of catkin maturity.

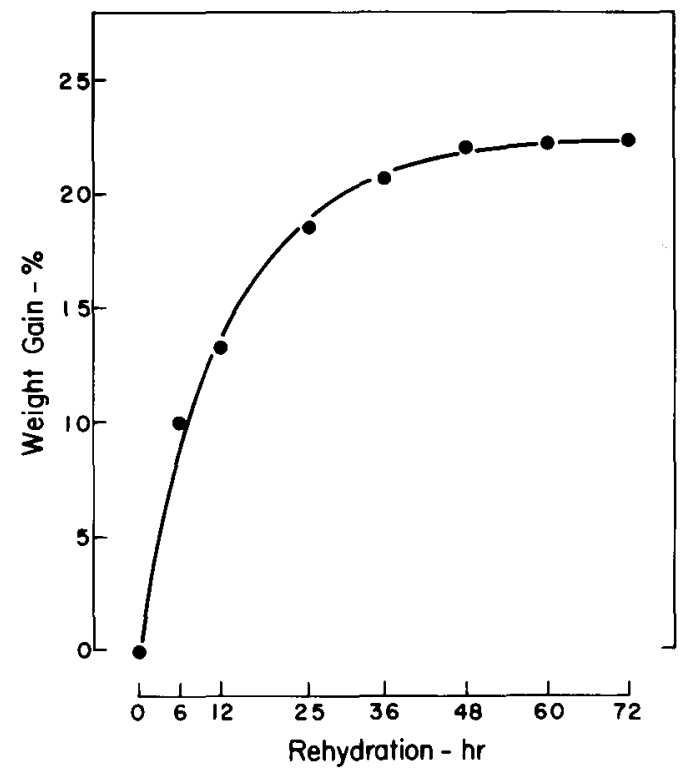

Fig. 3. Kinetics of dehydration of 'Stuart' pollen with time. The relationship is described by Mitscherlich's plant growth model: $\mathrm{Y}=$ $22.17\left(1-0.9774 \mathrm{e}^{-0.0796 x}\right), r^{2}=0.9673 . P \leq 0.01$. 


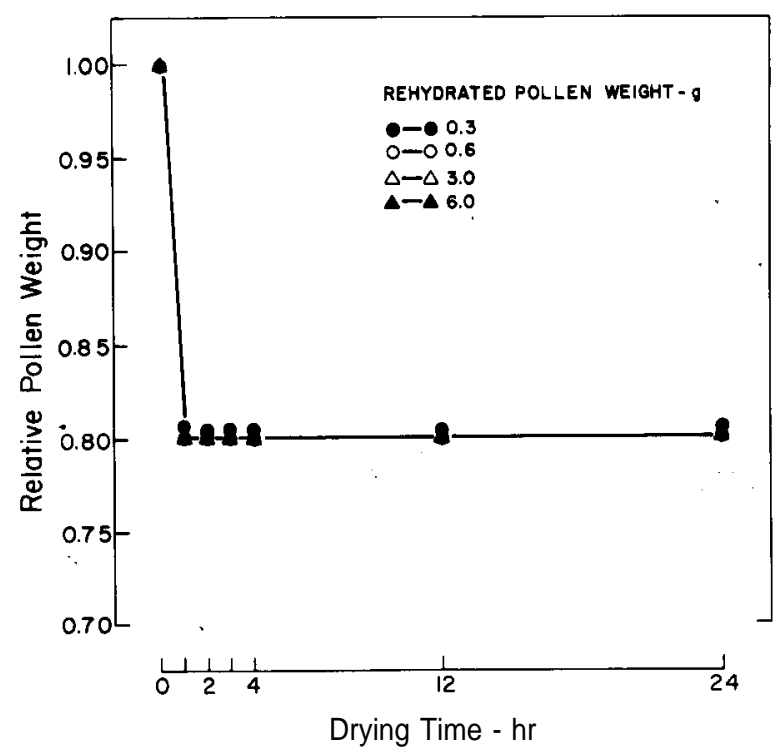

Fig. 4. Kinetics of dehydration of various quantities of 'Stuart' pecan pollen with time. The relationships are described by the following equations. For $0.3 \mathrm{~g}$ pollen: $\mathrm{Y}=0.7968+0.02001 / \mathrm{x}, r^{2}=$ 0.9258 , S.E.E. $=\& 0.021$; for 0.6 g pollen: $\mathrm{Y}=0.8001+0.0020$ $1 / \mathrm{x}, r^{2}=0.9894$, S.E.E. $=0.008$; for $3.0 \mathrm{~g}$ pollen: $\mathrm{Y}=0.8022$ $+0.00201 / \mathrm{x}, r^{2}=0.9964$, S.E.E. $= \pm 0.004$; for $6.0 \mathrm{~g}$ pollen: $\mathrm{Y}=0.8005+0.00201 / \mathrm{x}, r^{2}=0.9985$, S.E.E. $= \pm 0.003$. Regression coefficients are significantly different from zero. $P \leq$ 0.01 .

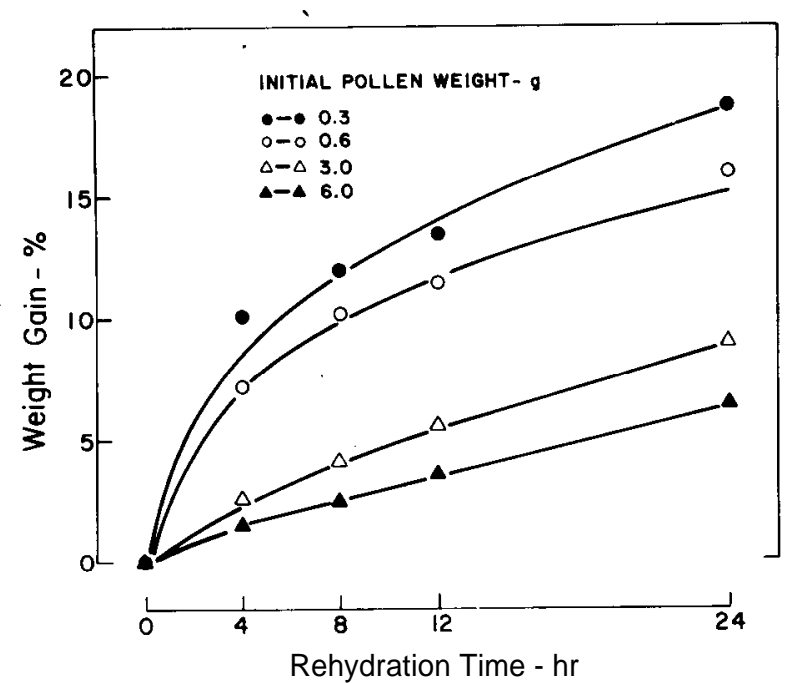

Fig. 5. Kinetics of dehydration of different quantities of 'Stuart' pecan pollen with time. The relationships are described by the following equations. For $0.3 \mathrm{~g}$ pollen: $\mathrm{Y}=-0.3479+13.2750 \log \mathrm{X}$, ? $=0.9755$, S.E.E. $= \pm 1.0 \%$; for $0.6 \mathrm{~g}$ pollen: $\mathrm{Y}=-0.758+$ $11.5583 \log \mathrm{X}, r^{2}=0.9702$, S.E.E. $= \pm 1.0 \%$; for $3.0 \mathrm{~g}$ pollen: $\mathrm{Y}=-0.2548+4.1170 \log \mathrm{X}+0.0056 \mathrm{X}^{2}, R^{2}=0.9949$, S.E.E. $= \pm 0.2 \%$; for $6.0 \mathrm{~g}$ pollen: $\mathrm{Y}=-0.1509+2.3343 \log \mathrm{X}+$ $0.054 \mathrm{X}^{2}, R^{2}=0.9716$, S.E.E. $= \pm 0.4 \%$. Regression coefficients are significantly different from zero. $P \leq 0.01$.

The time required for pecan pollen to reach a constant weight under dehydration conditions is much less than required under dehydration conditions. These results are similar to studies conducted on cereals that also demonstrate a much more rapid water loss than gain (Pixton and Warburton, 1971). The principles of diffusion coefficients and forces holding water in a biological system account for these differences (Pixton and Warburton,
1968). Moisture diffuses much more rapidly into air than into a complex biocolloidial system, as occurs during dehydration and dehydration, respectively. Furthermore, water held loosely in a biocolloidial system by capillary forces is more easily removed than that held by molecular forces. Even though we detected a differential rate of moisture uptake with respect to pollen quantity, we did not find a differential loss of moisture with respect to pollen quantity. During drying, weight was measured after $1 \mathrm{~h}$, which may have been too late to detect a differential diffusion rate of moisture among the pollen quantities.

Heslop-Harrison (1979) pointed out that pollen maturation and germination have inverted moisture regimes; that is, pollen becomes progressively dehydrated during maturation but rehydrated during germination on the stigmatic surface. The preparation of pecan pollen samples for storage and for in vitro germination presents a comparable condition. Yates and Sparks (1989) demonstrated that pollen dehydration was necessary for accurate estimations of the viability of pecan pollen by in vitro germination assays, and the current study demonstrates that dehydration increases the longevity of pecan pollen stored at - 12C. A model has been proposed that pollen contains both free and bound water (Dumas et al., 1984), which are probably analogous to the water held by capillary forces and by molecular forces, respectively, in cereal (Pixton and Warburton, 1968). We suggest that for successful storage of pecan pollen at $-12 \mathrm{C}$, the free water must be minimal. The free water maybe expected to vary with the stage of catkin maturity, the environmental conditions to which trees are exposed, and/or the conditions under which anther dehiscence occurs. Although there was a slight loss in viability with drying times $>1 \mathrm{~h}$, such a minor decrease would not be critical from a practical standpoint. Drying pollen before storage may not be necessary if anther dehiscence occurs at a lower RH than used in the current study, that is, in arid pecan growing regions. However, the expense of pollen collection and application, plus the potential loss in nut yield and the detrimental effects from selfing (Marquard, 1988; Sparks and Madden, 1985), are incentives for drying pollen before storage, regardless of environmental conditions during anther dehiscence and pollen preparation for storage.

Reducing moisture content of pollen before storage is beneficial for other species. Reduced moisture increased the length of time Zea mays (Barnabas and Rajki, 1981), Pennisetum glaucum (Hanna, 1990), and Pinus sp. (Matthews and Kraus, 1981) pollen could be stored. However, fertility was greater for Gossypium hirsutum pollen maintained at 20C at a high rather than a low humidity (Rodriguez-Garay and Barrow, 1986).

In summary, methodology has been developed that makes the long-term storage of pecan pollen possible with commonly available supplies and equipment. Dried pecan pollen can be packaged in moisture-proof bags to maintain viability, equal to that of freshly collected pollen, for at least 2 years when stored at $-12 \mathrm{C}$.

\section{Literature Cited}

Barnabas, B. and E. Rajki. 1981. Fertility of deep-frozen maize (Zea mays L.) pollen. Ann. Bet. 48:861-864.

Bennett, J., T. Koflanovich, and W.J. Stahmann III. 1986. Pecan growers' experiences with artificial pollination. Western Pecan Conf. Proc. 20:8-10.

Davis, J.T. and D. Sparks. 1971. Assimilation of ${ }^{14} \mathrm{CO}_{2}$ by catkins of Carya illinoensis and apparent translocation to the pollen. Amer. J. Bet. 58:932-938.

Dumas, C., R.B. Knox, and T. Gaude. 1984. Pollen-pistil recognition: 
New concepts from electron microscopy and cytochemistry. Intl. Rev. Cyt. 90:239-272.

Hanna, W.W. 1990. Long-term storage of Pennisetum glaucum (L.) R. Br. pollen. Theor. Applied Genet. 79:605-608.

Heslop-Harrison, J. 1979. An interpretation of the hydrodynamics of pollen. Amer. J. Bet. 66:737-743.

Marquard, R.D. 1988. Outcrossing rates in pecan and the potential for increased yields. J. Amer. Soc. Hort. Sci. 113:84-88.

Matthews, F.R. and J.F. Kraus. 1981. Pollen storage, p. 37-39. In: E.C. Franklin (cd.). Pollen management handbook. U.S. Dept. Agr. For. Serv. Agr. Hdbk. 587.

Pixton, S. W. and S. Warburton. 1968. The time required for conditioning gain to equilibrium with specific relative humidities. J. Stored Prod. Res. 4:261-265.

Pixton, S.W. and S. Warburton. 1971. Moisture content/relative humidity equilibrium of some cereal grains at different temperatures. J. Stored Prod. Res. 6:283-293.

Rodriguez-Garay, B. and J.R. Barrow. 1986. Short-term storage of cotton pollen. Plant Cell Rpt. 5:332-333.

Smith, C.L. and L.D. Romberg. 1933. Pollination control, period of receptivity, and pollen viability in the pecan. The Pecan Grower $1: 3,12$.

Snedecor, G.W. and W.G. Cochran. 1967. Statistical methods. Iowa State Univ. Press, Ames.

Sparks, D. 1986. Pecan, p. 323-339. In: S.P. Monselise (cd.). CRC handbook of fruit set and development. CRC Press, Boca Raton, Fla.

Sparks, D. 1987. Pollen shedding and stigma receptivity in pecan-a review. Annu. Rpt. Northern Nut Growers Assn. 78:127-140.
Sparks, D. and G.D. Madden. 1985. Distillate flower and fruit abortion in pecan as a function of cultivar, time, and pollination. J. Amer. Soc. Hort. Sci. 110:219-223.

Ware, G. O., K. Ohki, and L.C. Moon. 1982. The Mitscherlich plant growth model for determining critical nutrient deficiency levels. Agron. J. 74:88-91.

Wetzstein, H.Y. and D. Sparks. 1985. Structure and in vitro germination of the pollen of pecan. J. Amer. Soc. Hort. Sci. 110:778781.

Wlndham, W. R., F.E. Barton II, and J.A. Robertson. 1988. Moisture analysis of forage by near infrared reflectance spectroscopy: Preliminary collaborative study and comparison between Karl Fischer and

oven drying reference methods. J. Assn. Offic. Anal. Chem. 71:256262.

Woodroof, J.G. 1924. The development of pecan buds and the quantitative production of pollen. Ga. Agr. Expt. Sta. Bul. 144:134-161.

Woodroof, J.G. 1930. Studies of the staminate inflorescence and pollen of Hicoria pecan. J. Agr. Res. 40:1059-1104.

Yates, I.E. and D. Sparks. 1989. Hydration and temperature influence in vitro germination of pecan pollen. J. Amer. Soc. Hort. Sci. 114:599605.

Yates, I.E. and D. Sparks. 1990. Three-year-old pecan pollen retains fertility. J. Amer. Soc. Hort. Sci. 115:359-363.

Yates, I. E., T.E. Thompson, and J.L. Giles. 1986. Proper pollen storage, germination tests essential to success of artificial pollination. Pecan South 20(3):23-27.

Young, J.F. 1967. Humidity control in the laboratory using salt solutions-a review. J. Applied Chem. 17:241-245. 